\title{
WORKING TOWARDS DESIGN SOLUTIONS FOR THE WATER AND NUTRITION CRISIS OF INFORMAL SETTLEMENTS
}

\author{
C. CERRO \\ College of Architecture, Art and Design, American University of Sharjah, UAE
}

\begin{abstract}
According to the World Water Assessment Program, today, half the world's population lives in urban areas. Because of this, many of the world cities are growing exponentially and unchecked urban sprawl is spawning areas that lack water infrastructure. The vast majority of these people will be living in crowded informal settlements with inadequate, sometimes non-existent, water and sanitation services. The poor as always, are the first to suffer. Globally, an estimated 2,000 children (UNICEF) under the age of five die every day from diarrheal diseases and of these some 1,800 deaths are linked to water, sanitation and hygiene. Extending safe drinking water to the 180 million urban dwellers currently lacking it, will play a key role in improving the health and security of cities, protecting economies and ecosystems, and minimizing the risk of pandemics. With this in mind, this paper will cover an ongoing design process that started in 2012, for the development of water generating facilities to be implemented as independent, self-sufficient interventions within impoverished communities. Each one of the proposed buildings will use atmospheric water generators to produce water from the humidity in the air, which will be re-mineralized and stored for free access by the communities around them. A small percentage of the water produced will also be used to feed a mushroom and hydroponic vegetable farm within the building, designed to provide cheap and accessible nourishment to the neighborhood. Ultimately, a network of interdependent facilities could be placed around the informal settlements creating a hive that would function more as urban acupuncture than urban development, producing a financially feasible proposal designed to directly serve a community through architectural interventions that require minimal maintenance and the possibility of creating local jobs while helping solve the water and food crisis in informal settlements around the developing world.

Keywords: Atmospheric water generator, hydroponics, informal settlements, sustainability, urban acupuncture, urban farming, water.
\end{abstract}

\section{INTRODUCTION}

Our goal is to develop a proposal that is location specific by understanding the social context of the area of intervention, their present needs and their construction methods and materials together with the technologies present on site. To do this, we will be implementing a design approach called urban acupuncture, originally coined by Barcelonan architect and urbanist, Manuel de Sola Morales, and the term has been recently championed and developed further by Finnish architect and social theorist Marco Casagrande. Urban acupuncture [1] is an urban environmentalism design approach which combines urban design with the functional conceptual understanding of traditional Chinese acupuncture. This process uses small-scale interventions to transform the larger urban context. Sites are selected through an analysis of social, economic and ecological factors and developed through a dialog between designers and the community. The goal is to produce small-scale but socially catalytic interventions into the urban fabric. By perceiving the city as an organism, urban acupuncture promotes communitarian interdependence and sets localized points of intervention where it is deemed that the biggest potential to regenerate the urban fabric exists. This approach 
is especially beneficial in the developing world where the government and institutions have limited resources. On the following pages, I will be presenting one of our ongoing projects designed with the premise of urban acupuncture in mind, to solve water scarcity problems in informal settlements. The proposal will go further than attaining its main goal. It will also identify secondary societal problems within the affected communities and propose solutions by the development of interdependent systems to create a multifunctional intervention.

\section{THE PROBLEM: WATER SCARCITY IN INFORMAL SETTLEMENTS}

For the first time in history, more than half of the world's population is living in urban areas. According to UN-Habitat, around $33 \%$ of the urban population in the developing world (in 2012) lived in informal settlements. That is, about $863,000,000$ people need access to water, making the attainment of universal and equitable access to safe and affordable drinking water for all by 2030 as proposed by the United Nations in the sixth sustainable development goal [2] a major challenge, particularly in urban informal communities. Although $0.014 \%$ of all water on the Earth is both fresh and easily accessible (of the remaining water, $97 \%$ is saline and a little less than $3 \%$ is hard to access), technically, there is sufficient freshwater on a global scale for humanity to fulfill its needs. In recent decades, due to unequal distribution and climate change, that results in drought and floods around the world, plus a sharp rise in global freshwater demand, humanity is facing a water crisis, with demand expected to outstrip supply by $40 \%$ in 2030, if current trends continue [3]. Attaining universal and equitable access to safe and affordable drinking water for all by 2030 (sustainable development goal 6) will be a major challenge, particularly in urban informal settlements. In India, some slums are recognized, by the government, which give the inhabitants property rights and access to city services, including connections to the water supply. The problem is that $59 \%$ [4] of slums are not recognized. Even when public health and economic reasons are present for providing informal settlements with access to the municipal water supply, lack of property rights impedes provision of this vital service.

\section{EXISTING WATER VAPOR HARVESTING SYSTEMS}

The water in the atmosphere makes up for only a very small percentage of the total water on the planet. But from a human consumption perspective, this is a lot of water, and at any given time, there are 3.1 quadrillion gallons of water in the atmosphere. A resource that presently has remained underutilized. The following are a list of some modern humidity-based systems that we have been studying with the purpose of finding the right technologies for some of our urban acupuncture interventions. All are dealing with humidity in the air, and all were studied in terms of production feasibility in terms of cost and location.

\subsection{Fog harvesting}

To understand this harvesting system, first we need to understand fog. Cold air holds less moisture than warmer air does, creating a natural fluctuation in air temperature which results in water condensing out of the air mass as dew. Fog collection happens when suspended droplets of dew collide with a vertical net. This net catches the water, which thanks to gravity, and runs down into a collecting drain at the bottom of the net that then takes the water into a tank. Fog collection is not a new approach, and it has been practiced and documented around the world for ages; inhabitants of the Canary Islands have been harvesting fog drip as a source of 
water for roughly 2,000 years [5]. In Palestine, small honeycombed ceramic walls were built around plants to catch the mist and channel it towards the plant trunk and roots. In the Atacama desert in Chile, fog collection was accomplished via piles of stones that were arranged so that the collected water would trickle down the center when fog passed over them. Modern fog interception technology was first introduced in the mid-1980s, by the Meteorological Service of Canada, who began constructing and deploying large fog collecting devices on Mount Sutton in Quebec. These simple tools consisted of a large piece of canvas stretched between two wooden poles held up by guide wires, with a long trough underneath. Water would condense out of the fog onto the canvas, merge into droplets and then slide down to drip off of the bottom of the canvas and into the collecting trough below. More modern systems for fog harvesting technology consist of a single- or double-layer mesh net supported by two posts rising from the ground. Mesh panels can vary in size. The mesh is usually made of nylon, polyethylene or polypropylene netting which can be produced to various densities capable of capturing different quantities of water from the fog that passes through it. The collectors are positioned on ridgelines perpendicular to prevailing wind and capture and collect water when fog sweeps through them. The number and size of meshes chosen will depend on the local topography, demand for water and availability of financial resources and materials. Nowadays, there are active fog harvesting projects in Yemen, Morocco, Chile, Peru, Ghana, Eritrea, Ethiopia, South Africa and California. Fog nets are also inexpensive to produce, and they have almost zero maintenance costs. Once poor communities understand the benefits of this water-collecting system, it will be adopted worldwide, helping to reduce migration pressures.

\subsection{Cooling condensation}

In a cooling condensation atmospheric water generator (AWG) (Fig. 1), a compressor circulates refrigerant through a condenser and then an evaporator coil cools the air surrounding it. This lowers the air temperature to its dew point, causing water to condense. A controlledspeed fan pushes filtered air over the coil. The resulting water is then moved to a holding tank with purification and filtration system to help keep the water pure [6] and reducing the risk posed by viruses and bacteria which may be collected from the ambient air on the evaporator coil by the condensing water. The rate at which water can be produced depends on the relative humidity, ambient air temperature and size of the compressor. The higher relative humidity and ambient air temperature will result in a more effective water production. As a rule of thumb, cooling condensation AWGs do not work efficiently when the temperature falls below $18.3^{\circ} \mathrm{C}\left(65^{\circ} \mathrm{F}\right)$ or the relative humidity drops below $30 \%$ [7].

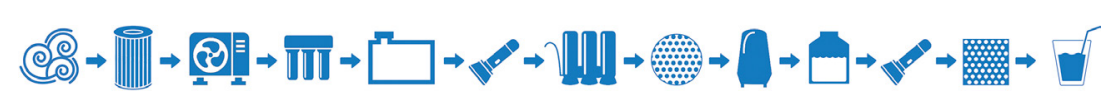

Figure 1: Air, electrostatic air filter, condenser, sediment filter, condenser tank, UV sterilization, carbon filter system, RO filter membrane, remineralization system, drinking water tank, UV sterilization, micro filter and drinking water. 


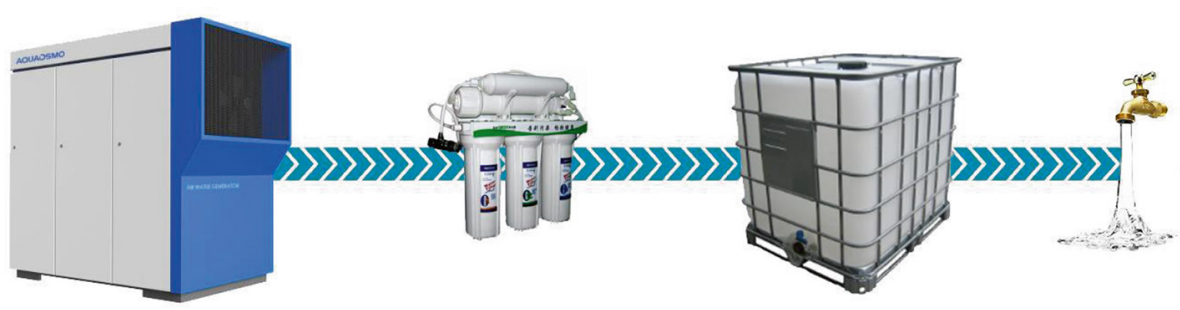

Figure 2: Atmospheric water generator, filtering or remineralization and storage and use. In some units, the filtering happens within the unit itself.

\subsection{Wet desiccation}

Wet desiccant water generation involves the use of salt in a concentrated brine solution to absorb the ambient humidity. These systems then extract the water from the solution and purify them for consumption. These technologies are normally used by the US military and the Federal Emergency Management Agency [8].

For this project, we decided to use the Skywater 300 AWG (a cooling condensation system) by Skywater which is capable of producing 300 gal $(1,100 \mathrm{~L})$ of water a day. Its size allows us to use eight units on this project, with a total production of around 2,400 gal $(9,000 \mathrm{~L})$. But the market is saturated with units, and at the end, we would use the best unit for the location of the project, and this means that we have taken into consideration a lot of factors external to the working of the equipment. The AWGs will produce water, which will be filtered and stored for consumption (Fig. 2).

\section{METHODOLOGY}

The micro atmospheric water generation urban farm and market proposal was designed as an attempt to produce solutions to the problem of water scarcity in informal settlements through developing an architectural intervention using an urban planning technique called urban acupuncture. To do this, we developed the following methodology:

- Conduct on-site analysis that includes local government departments and small-scale water providers, both private operators and NGO-run entities, as well as consultations with men and women and boys and girls on the issue of accessing water, such as roles in collecting water, uses, distances to access points, cleanliness of water and others.

- Produce an implementation plan on the selected informal settlement choosing sites with vehicular access and electric supply.

- Identify implementation contractors and viable local technologies for the construction of the project. Construction centers need to be in the proximity of the area of implementation.

- For project implementation, reach consensus and agreements on the contributions and roles and responsibilities of stakeholders and implementers.

- Implement one or more atmospheric water generating towers for improved water delivery and access in each selected informal settlement.

- Conduct training of the personnel that will maintain the facility and operate the urban farm and market.

- Establish mechanisms for transparent and participatory project monitoring and evaluation. 
- Conduct community-based water quality monitoring program and household water purification campaign.

- Prepare and launch public information campaigns in support of the improved access to water facilities.

- Monitor usage to produce real data of the evolution of the project.

This methodology is characterized by punctual interventions, rather than a heavy-handed tabula rasa approaches; urban acupuncture aims to contribute to the activation of neighborhoods where community regeneration can unfold naturally with the introduction of the appropriate catalyst. In our case, the catalyst is our design proposal, in terms of its function. The key difference in using an urban acupuncture approach is that it acknowledges that strong communities cannot be created instantaneously by designers, but rather requires time with the help from the designer, government and the community itself [9]. Informal urbanism does not happen in a vacuum, and it often needs the correct set of physical and social circumstances to provide motivation and inspiration. This is why the site location becomes the most important aspect of the methodology if the design proposal is to succeed. In beginning, to form a design response that holds true to the research conducted on the ways in which strong communities are forged, the first step is to identify a location within the neighborhood where an intervention might have the greatest impact, understanding our primary goal (water production) but being open with our secondary and tertiary goals as to adapt to the other needs of the site.

\section{WHAT IS THE ADVANTAGE OF USING SHIPPING CONTAINERS?}

The ISO Shipping Container is a terrific piece of hardware as it is cheap, sturdy, corrosion resistant and modular. With over 17 million shipping containers in the world, and five or six million of them currently shipping around the planet on vessels, trucks and trains, the shipping container is not only easy to move around the world, but readily available. Presently, there are 30 million unused containers globally. That is a result of offer and demand. Ships loaded of goods arrive from China, but no one will pay for empty containers to be shipped back, so the containers left until used. Countries that import more than they export will have a surplus. The idea behind this proposal is to reuse these old shipping containers as the main structural and enclosure systems for the unit envelope. The average life expectancy for a shipping container to be used in cargo transportation is between 10 and 12 years. After leaving the service, the shipping container is still structurally sound, and being a modular element, it is easy to stack and transport allowing for the housing units to be prefabricated and brought in parts to the site. Containers are designed to mostly take vertical loads, making them earthquake and hurricane proof, which makes them extremely safe for natural disaster-prone areas. Building a structure out of a shipping container takes roughly $2-3$ weeks in comparison to brick and mortar structure which takes around 4-6 months to make. The idea is that the containers would be outfitted in a prefabrication process that would take place offsite. A standard shipping container can hold the weight of up to 10 other containers (up to 24 tons), making it the perfect modular structural element for vertical construction. This system will also allow us to enlarge the facility as needed, thanks to the modularity provided by the shipping container.

\section{DESIGN PROCESS: THE PATH TO WATER SELF-SUFFICIENCY}

From the beginning, our aim was to find an impermanent settlement as the site for the project because in this type of localities we had the potential to benefit the largest amount of people. Our final grouping of possible sites included: Ciudad Neza in Mexico City; Khayelitsha in 


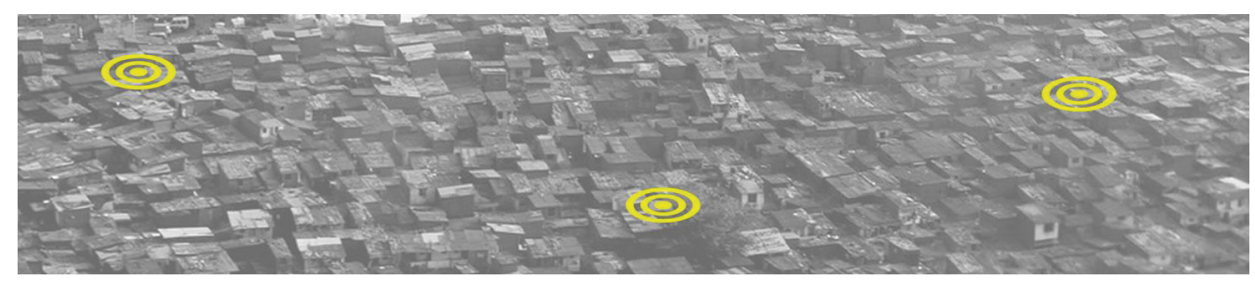

Figure 3: Proposed site location diagram in Dharavi, Mumbai, India. The actual sites would have to be chosen by the city government.

Cape Town, South Africa; Kibera in Nairobi, Kenia; Orangi Town in Karachi, Pakistan; and Dharavi in Mumbai, India. According to some estimates, Mumbai, India, has the largest slum population than any city in the world, with more than half of its 18.5 million people living in informal settlements. Because of a high ratio of people per square kilometer and due to its density, we chose to focus on the locality of Dharavi. Founded in 1882, during the British colonial period, this informal settlement is the second largest in Asia, with an area of just over $2.1 \mathrm{~km}^{2}$ and a population of 300,000 to about $1,000,000$ people [10]. Potable water is supplied by the Brihanmumbai Municipal Corporation to Dharavi and the whole of Mumbai, but there is a large amount of water lost to water thefts, illegal connection and leakage. Today, most homes in Dharavi do not have connections to utility services, and the existing distribution systems are not clean and waste the resource. Because of these complexities and the density of population, and the fact that Mumbai is a very humid place with an annual relative humidity of $74.9 \%$, Dharavi is the perfect site for an intervention using urban acupuncture. The project would minimize displacement of people by keeping a small footprint, produce local jobs and maximize the scope of the project area of influence (Fig. 3). Also, Mumbai is a very humid place with an annual relative humidity of $74.9 \%$ (between $69 \%$ low and $86 \%$ high). This makes it the perfect venue for the use of AWGs. The advantage of this system is that the more the humidity in the air, the more effective the system is.

The design process started with a program which as you will see below kept changing. The present design requirements had to be affordable, prefabricated and easy to put together. But from our side, based on our field experience, it also had to be sustainable and it needed to go further than just providing an answer to water production. As a catalyst, it had to do more and it had to provide jobs and use the water to solve other problems. It needed to become an urban acupuncture project. The proposal was originally going to be a government-linked project, expediency was important and politicians want to take credit for the projects they sponsor. Ultimately, the project was never taken up by the government, and we are presently looking for other options to expedite implementation. For now, the project remains as a proposal with a long evolving life.

It started in 2012 when we were working on designing a reinterpretation of the water tower. Until now, water towers had a very standard design. Normally composed of an elevated structure supporting a water tank $\mathrm{k}_{2}$ it constructed at a height sufficient to pressurize a water supply system for the distribution of potable water and to provide emergency water storage for fire protection. We see them in every new neighborhood all across the United States and Europe. In its early age, our project was not concerned with the production of water as much as it was with developing a function for all that water stored on the tower while not in use. The idea was to develop a hybrid of functions with social potential for the 


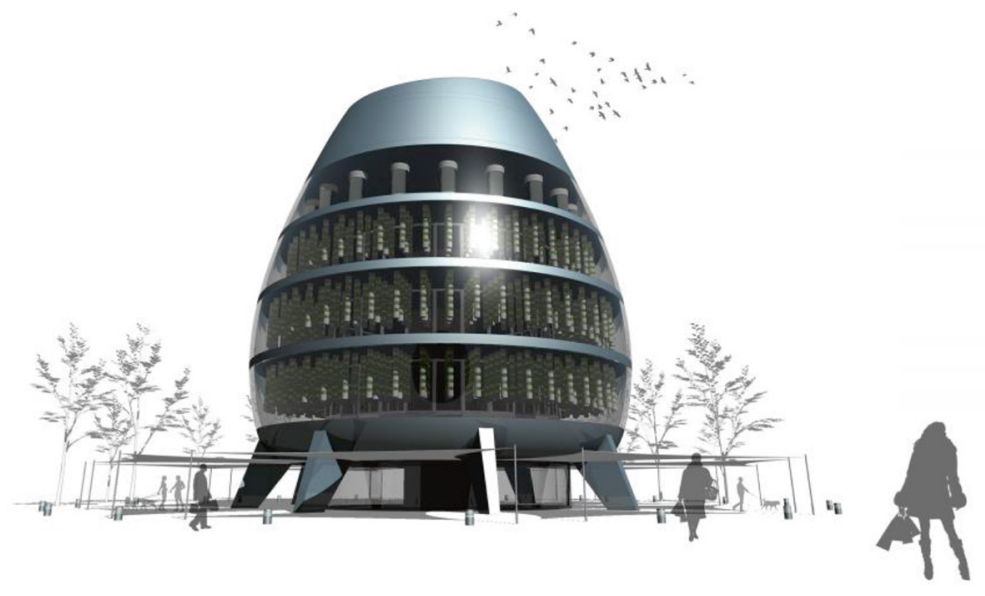

Figure 4: Water tower, hydroponic farm, aquaponic facility and market hybrid.

type of location usually used for the placement of water towers. After studying precedent for some time, we started by flattening the top of the building to allow for placement of solar panels. The building was designed (Fig. 4) with a circular plan to create a concentric distribution for its functions. Because stagnant water can be dangerous for drinking because it provides a better incubator than running water for many kinds of bacteria and parasites, the main objective of the building would be to keep the water in motion. To do so, solar energy is used. The space under the tank would be transformed into an enclosed volume to house the new water-dependent functions. Directly on the floor under the tank, the water would feed into an aquaponic facility.

Aquaponics is a system that combines conventional aquaculture (raising aquatic animals like snails, fish, crayfish or prawns in water tanks) with hydroponics (cultivating plants in water) in a symbiotic environment. In normal aquaculture, excretions from the animals being raised can accumulate in the water, increasing the toxicity. But in an aquaponic system, water from an aquaculture system is fed to a hydroponic system where the by-products are broken down by nitrifying bacteria initially into nitrites and subsequently into nitrates that are utilized by the plants as nutrients. The water is then recirculated back to the aquaculture system, which meant that the floors under the aquaponic facility would have to be composed of a hydroponic farm to be able to create a functional water cycle. Hydroponics is a method of growing plants without soil by using a mineral nutrient solution dissolved in water. Terrestrial plants may be grown with only their roots exposed to the mineral solution. The nutrients in hydroponics can come from an array of different sources, one of which is fish waste. So the design created a hybrid of three functions linked by creating a water cycle. The water from the tank would feed the fish which in turn would feed the plants in a continuous cycle that kept the water in motion until used for its normal function. Since these towers are normally set in open fields, the ground floor was turned into an enclosed market in the winter and an open market in the summer, where the community would be able to purchase at a lower price (because there were no transportation costs) the produce and fish that came from the facility, hence using an existing infrastructure to bring better and cheaper nutrition to the community. The space on the ground level would then become a social catalyst for other activities, and types of commerce not necessarily directly linked to the main function of the building. In this form, design starts a possible transformation that is taken over and further developed by the 


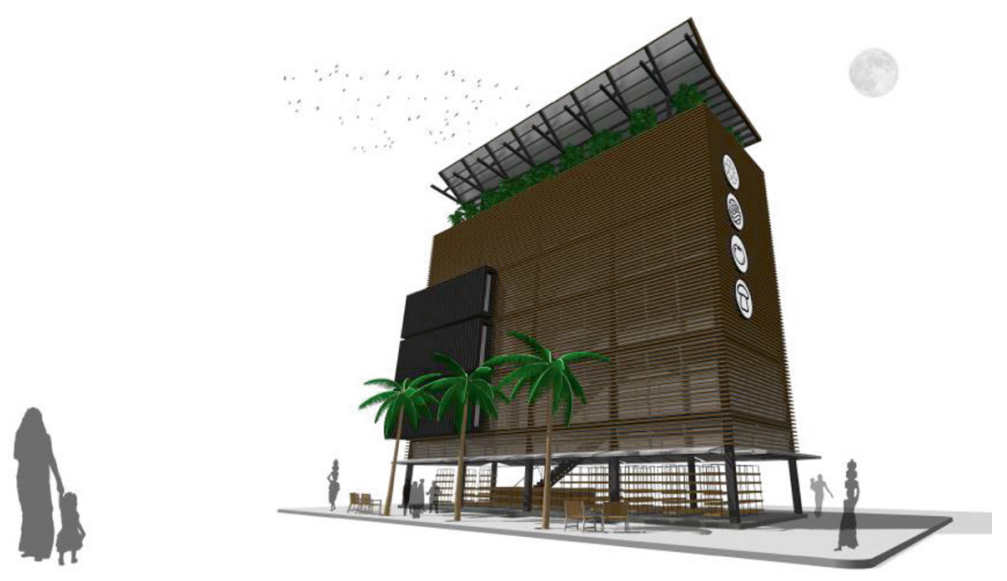

Figure 5: Atmospheric water generators, hydroponic farm, fungiculture facility and market hybrid.

community. And it is interesting to see that the design ideas even at its earliest proposal were already dealing with the implementation of urban acupuncture ideologies.

The idea kept evolving and manifested at a smaller scale in some work on floating dwelling that we were engaged in until it reappeared in 2018 as part of a new proposal presented on a paper for the Sustainable Environment and Urban Infrastructure International Conference in Dubai, in the UAE [11], and then as a poster at the 106th annual meeting of the Association of Collegiate Schools of Architecture conference [12], themed 'The Ethical Imperative' In Denver, in the USA. On these paper and poster, a new component took front stage: the AWGs. The problem had shifted from 'what to do with existing water?' to 'not having clean water', and at the time, we were trying to figure out how to provide large amounts of water to populations in need within informal settlements. Our research took us into fog harvesting, and while this system worked well in suburban projects, the high density of the informal settlements made it very hard to use due to the lack of space. This is where we started experimenting with AWGs. We found a cost-effective unit that would produce 1,100 L of water a day, to take over the function of the water tank on the previous skim. But we needed to produce a lot of water, so the new tower was designed to house eight AWG units capable of producing 9,000 L of water a day. The idea behind this proposal (Fig. 5) is to try to solve an existing problem and by doing so expanding the realm of the solution to tackle other site issues. The main problem was the lack of clean and accessible water in the proposed community. To deal with this problem, the proposed building would house a number of AWGs in its upper floors. Height is of importance because it gives the building access to humidity above the existing housing skyline around its location. The water produced by the generators would then be filtered and stored in water tanks around the building above the ground floor. This would allow us to use gravity as a means of moving water down for public consumption. As the building would be storing water, just like on the first water tower design, this project would also help the community by producing cheaper food. The cost of fresh produce is dependent on transportation costs. By producing local food, the building is eliminating transportation costs and would provide the community with fresh produce at a lower cost. To do so, the tower would also become a vertical farm, using a combination of soil-based and hydroponic farming systems to grow fruits and vegetables. Hydroponic gardening uses only 1/20th of water compared 


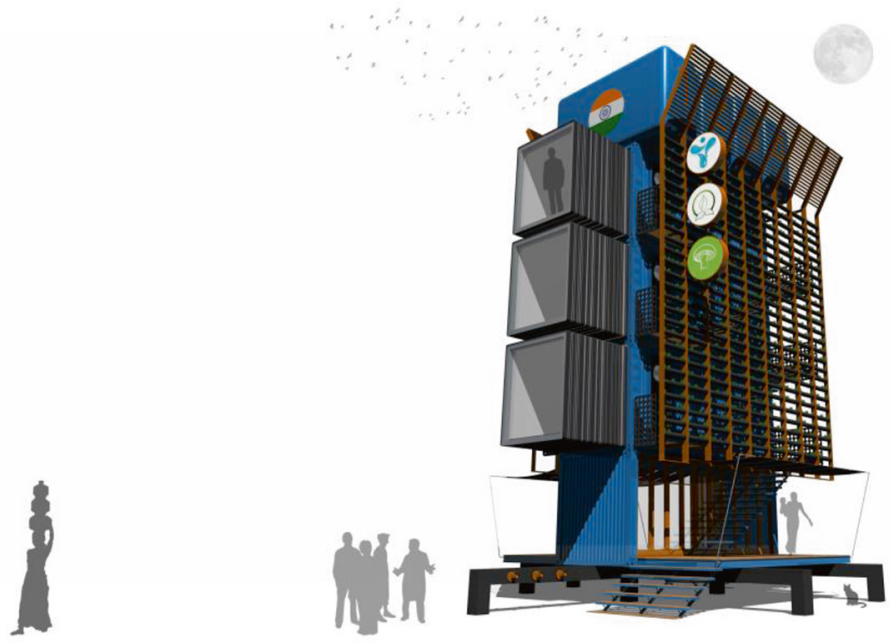

Figure 6: Water tanks, atmospheric water generators, hydroponic farm, fungiculture facility and store hybrid.

to traditional (soil based) gardening. Because it provides a sterile environment for plants, it does not require pesticides, fertilizers and other chemicals, as there is no chance of damage due to soil-borne diseases or pests. The system also grows crops two times faster than normal farming and uses less space. Adding to this, the tower would also produce different types of mushrooms by using a number of fungi-culture pods. In this manner, the project combines a water production and storage facility and a hydroponic vertical farm and a mushroom farm to develop an interdependent system that works year around and in a semi-self-sufficient way for the benefit of the immediate community. The ground floor, just like on the water tower design, would serve as a market to manage water access and sell the produce of the towers. The project would also create jobs for the community during the construction period and for the maintenance and management of the unit.

After our first visits to the site, we realized that the construction materials proposed for the design of the project would increase its cost because although those materials were present in the site, they were not local and had to be imported. This issue took us again into a redesign of the idea which was presented as an entry for the UNBOX competition in 2018 (Fig. 6). We used the opportunity to reassess costs trying not to change the ideas behind the design process. In essence, the project remained having the same components with some basic changes. The structure is composed of four $20^{\prime}$ containers that house the different functions in a vertical prefabricated structure. The facility itself would house four AWGs on the highest container with four large water tanks directly above them. Containers 2 and 3 would house mushroom production, and the sides of the structure would house hydroponic vertical farms.

Although the cost of this version was considerably cheaper, we realized that having fluctuating loads in the water tanks as they got filled and emptied would generate structural problems. The tanks needed to be brought to the ground level or placed underground. And the unit was too small to produce consequential amounts of food or enough water. So we kept working on this proposal and arrived to the present version (Fig. 7), which was presented at the Water Pollution conference, organized by the Wessex Institute, in A Corruña, Spain, on 


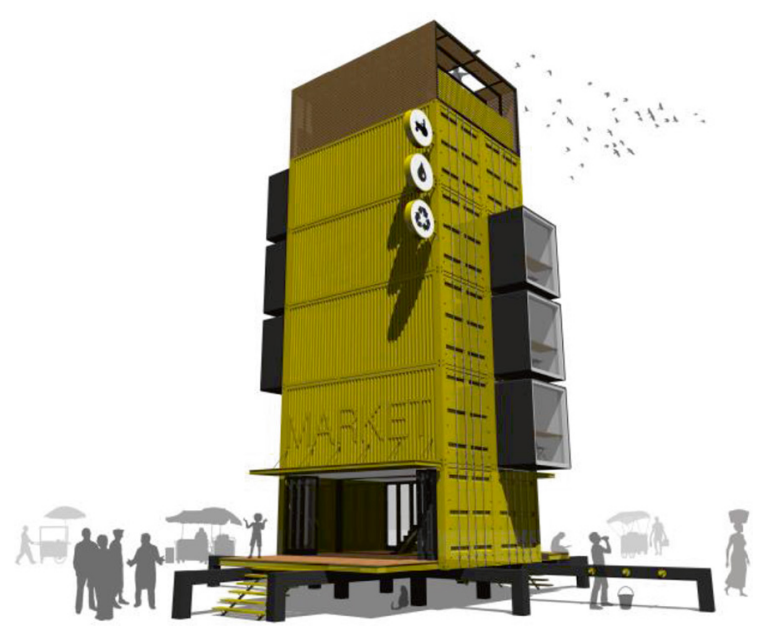

Figure 7: Atmospheric water generators, hydroponic farm, fungiculture facility and market hybrid with water tanks buried under the structure.

May 2018 [13]. This present (Fig. 8) version is also designed with $20^{\prime}$ long shipping containers. The building is lifted off the ground by a metal spider structural foundation that allows for the volume to adapt to different ground topographies. It also helps give maintenance access from under the structure to the storage water tanks that have been buried under the building. The first level is composed of two side-by-side shipping containers, with the side

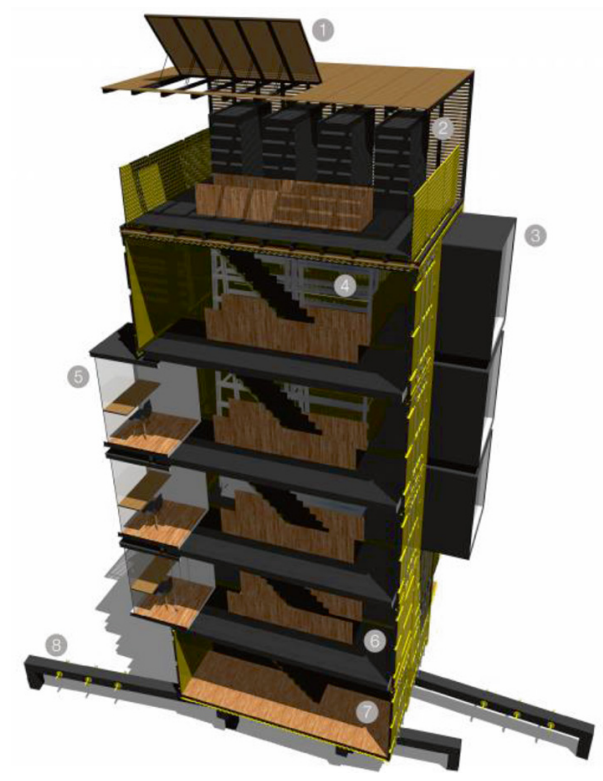

Figure 8: 1. Solar panels, 2. Atmospheric water generators, 3. Composting toilets,

4. Hydroponic farm, 5. Office/sleeping/packaging space, 6. Mushroom farm,

7. Market, 8. Free water access. 
panels removed to allow for access in both longitudinal directions to the interior of the building. Two large decks attach to the longitudinal sides adding exterior surface area, linking the decks to the ground, and a large set of stairs also serves as sitting areas. This level functions as a market, designed to sell the food produced within the building. The food produced is cheaper because it is produced locally, cutting the transportation and packaging costs from the overall food price. The second level is composed of two shipping containers and a popout volume that serves as an office. This level is designed to be a mushroom farm. Mushroom farming requires a dark well-insulated space to keep the temperature constant and with no windows but good ventilation to prevent carbon dioxide built-up. Mushrooms grow fast and are incredibly nutritional, a great addition to anybody's diet. The units are meant to function as a hive with 10 or 15 working together in a locality. This would allow for some of the units to be more specialized on one production over the other or to allow for other elements like a clinic to be brought into the system since there would be other markets to sell the production of the unit that has its first level displaced by another function needed by the community. But for these proposals, we are dealing with a hybrid unit. Levels 3-5 house two large spinning hydroponic towers, designed to produce green leaved vegetables under purple grow lights. These three levels are also composed of side-by-side shipping containers. But with the exception of circulation, the three levels are open vertically to house the hydroponic equipment, water pumps and light systems, making a single three-level room.

The pop-out volumes on this section of the project serve as a management office, packaging spaces, a sleeping area for the night guard and a composting toilet placed on the uppermost unit. The top level is a louvered open space designed to house the eight AWGs, which will be set in two rows with one row stacked on top of the other. The generators are self-housed units with specific placement requirements. They are lined up to absorb vapor from the atmosphere with enough space around each of them for maintenance. The unit will clean the water itself and will store it before sending it to the main storage tank under the building. Before accessing the water at the ground level, another filter will clean it again and re-mineralize it before it can be consumed. This is done because just like with desalinized water, AWG water is dead water, meaning that all minerals have been removed in the process. The top of the sixth level has an adjustable solar panel system, designed to feed energy to a tesla battery inside one of the office volumes. The energy produced is meant for the everyday working of the building but not for the AWGs. These units use too much electricity and will need to be connected to the main city grid or develop a solar setup on the buildings surrounding the water tower to provide enough electricity. On the ground level, a person will have access to water $24 \mathrm{hr}$ a day from faucets installed on the structural legs of the building. Multiple faucets will allow large numbers of people to access water simultaneously. Wasted water will be reclaimed by a drainage system under the water dispensing area, go through a filter and get re-stored on the main tank to minimize waste due to leakage. An internal stair connects all the levels vertically. The buildings will be constructed using prefabrication techniques, but this will be done within the community so as to create jobs during the construction process. After the buildings are finished, more locals will be hired and trained to work, maintain and manage the facility. By selling the produce and mushrooms, a fund will be set for paying for salaries and the upkeep of the building, allowing the water to be provided free of cost to the population. Another consideration to keep in mind is that the building is versatile enough due to the modularity allowed by the use of shipping containers that it can increasing its width by the addition of another set of containers to create more space for more equipment or food production as needed. This allows the building to increase its water production as needed by adding AWGs. 
The site has a main road (Dharavi Depot Road) which would provide for access of equipment and easy maintenance. The idea is to place the towers at different intervals within this main road, allowing for construction equipment to arrive easily to the site, including the cranes that will be needed for the stacking of the shipping containers.

\section{COST AND IMPLEMENTATION}

The question of cost has been a very important concern on the development of this project. On one hand, the urban acupuncture approach will always be cheaper than providing infrastructure to a large community that does not have it. Historically, governments are not prepared to tackle the financial cost of solving the problems of informal settlements. If they were, the informal settlements would not exist. The urban acupuncture approach needs to have a level of adaptability and to do so a level of detachment of esthetic parameters and formal ideas because the design will change from site to site depending on socio-economical parameters present at the different locations. As the famous quote by Louis Sullivan states, 'form follows function', but it also needs to be dependent on local materials and means of construction. Our approach has taken a specific form in the context of the proposed site in Mumbai, but if the project is implemented somewhere else, its form would be entirely dependent on the materials and construction means accessible to the different populations of the proposed sites. The overall technology is not inexpensive; each AWG is about $\$ 4,000.00$ dollars plus maintenance costs for a $500 \mathrm{~L}$ daily production. But the cost can be offset by donations from companies that would want to be associated with the project, UN loans or other diverse financial options to be studied in relation to the financial potential of each site. The materiality of the project has also been a concern. Ultimately, the purpose of an urban acupuncture approach is to adapt to the potential of the community, and in the case of Mumbai, we have simplified the building by using shipping containers as our base material. The reasons for this choice will be explained on the next header. The cost of a prototype will always be higher as a single unit, but once a contract is selected to build a number of units, the price will drop. The more orders will allow for the system of prefabrication to cheapen costs since an assembly process would be stablished and reused. Ultimately, the larger expense will be for the AWGs and other technologies within the building. The cost of the building is nominal.

For implementation in Dharavi, the shipping containers would be purchased at The Port of Mumbai (same city as the site), and they would be taken for construction and assembly to one of the industrial zones in the periphery of Dharavi. The original idea is that the project would be sponsored and maintained by the Municipal Corporation of Greater Mumbai Water Department. But there are risks and barriers to implementation, and the logistics of construction will require a local company with local experience, but the larger problems will happen at the political and gubernatorial levels. To deal with this, we have found that projects associated with specific NGOs have a larger potential of implementation. So we are on the process of exploring that route in search for an appropriate sponsor to present the project directly to the pertinent authorities.

\section{CONCLUSION}

As the population of cities in the planet continues to grow, resources and infrastructure will become more and more scarce in poor areas. Designers have an ethical responsibility to help solve the problems that arise from overpopulation. But to do so, we will need to adapt to new design techniques that are capable to efficiently function in low-income communities which are never priorities for their government. The goal of urban acupuncture is to do this 
by producing small-scale but socially catalytic interventions into the urban fabric, which provides us (designers) the opportunity to produce social design at low cost but with transformative results within communities in need. In that sense, we learned from being in the field the social complexities of trying to do work in informal settlements. These complexities had little to do with our proposal and a lot more with the different powers at play in the community. Our attempt to design an affordable, prefabricated and easy to put together project was the easy part of the endeavor. Finding a way to implement it has taken a lot of time and energy without providing a light at the end of the tunnel. The project works in terms of its design requirements and program, and the community could use it because addressing water scarcity indirectly helps to deal with hunger, sanitation problems and disease. All of which influence education, economy and life span, which are the pillars for having a better quality of life. But until implemented, we will not be able to see how it evolves and adapts to the real needs of the community. This project proposes a new typology on self-sufficient infrastructure designed to better the quality of life by helping achieve the United Nations global goals for sustainable development [14].

\section{ACKNOWLEDGEMENT}

This research was supported by the American University of Sharjah and the College of Architecture, Art and Design.

\section{REFERENCES}

[1] Lerner, J., Urban Acupuncture: Calibrating Pinpricks of Change That Enrich City Life, Island Press: Washington, DC, 2014.

[2] Open Working Group Proposal for the Sustainable Development Goals, United Nations: New York, available at https://sustainabledevelopment.un.org/content/ documents/1579SDGsProposal.pdf, 2014 (accessed 7 November 2017).

[3] Boltz, F., How Do We Prevent Today's Water Crisis Becoming Tomorrow's Catastrophe, World Economic Forum, available at https://www.weforum.org/agenda/2017/03/ building-freshwater-resilience-to-anticipate-and-address-water-crises/, 23 March 2017 (accessed 6 April 2018).

[4] National Sample Survey Organization, Key Indicators of Urban Slums in India. National Sample Survey 69th Round, July 2012-December 2012, Ministry of Statistics and Programme Implementation: New Delhi, available at, 2013 (accessed 19 August 2015).

[5] Marzol, M.V., La Captación del Agua de la Niebla en la Isla de Tenerife, Spain: Servicio de Publicaciones de la Caja General de Ahorros de Canarias: Las Palmas de Gran Canaria, 2005.

[6] Obispo, S.L., California system generates drinking water from moisture in the air. Membrane Technology, 2009(11), p. 7, 2009.

[7] Greenfieldboyce, N., Water Extracted from the Air for Disaster Relief, National Public Radio, 19 October 2006.

[8] Totty, M., Innovation Awards: Ahead of the Pack, Wall Street Journal, 30 October 2007. http://www.wsj.com/ad/article/acurainnovations-071030.html.

[9] Dovey, K., The aesthetics of space. Aesthetics, Well-Being and Health: Essays Within Architecture and Environment Aesthetics, ed. B. Cold, Ashgate: Burlington, VT, p. 96, 2001. https://www.worldcat.org/title/aesthetics-well-being-and-health-essays-withinarchitecture-and-environmental-aesthetics/oclc/47118697. 
[10] Risbud, N., Slums: The Case of Mumbai, India, School of Planning and Architecture: New Delhi. https://www.ucl.ac.uk/dpu-projects/Global_Report/pdfs/Mumbai.pdf.

[11] Cerro, C., Developing Solutions for Dealing with Water and Food Scarcity: Atmospheric Water Generator and Urban Farm Tower, IEEE, 2018, Electronic ISBN-978-1-53862399-2, (POD) ISBN: 978-1-5386-2400-5, DOI: 10.1109/CASET.2018.8376754.

[12] Cerro, C., Atmospheric Water Generating and Urban Farm Tower, ACSA Press: UK, p. 157, 2018, http://www.acsa-arch.org/docs/default-source/conferences-files/106am_ project_proceedings-small3.pdf?sfvrsn=0.

[13] Cerro, C., Urban Acupuncture: Producing Water in Informal Settlements, WIT Transactions on Ecology and the Environment, Vol. 228, p. 9, WIT Press: UK, 2018 https://www. witpress.com/elibrary/wit-transactions-on-ecology-and-the-environment/228/36648.

[14] United Nations, Transforming Our World: The 2030 Agenda for Sustainable Development, UN Publishing: New York, 2015. 